\title{
Chemical composition of rocket, thyme and parsley essential oils and their effect on some fungi and aflatoxin production
}

\begin{abstract}
Aims: Determination the chemical compositions of essential oils from parsley, rocket seeds and thyme leaves and evaluate their effect at different concentrations on some dominant fungi on wheat grains and aflatoxin production.

Methods and results: The chemical compositions of the oils were determined by using Gas Chromatography Mass Spectrometry (GC-MS). The antimicrobial activities of the tested essential oils were examined using the agar well diffusion method. Determination of aflatoxins was carried out using (HPLC) after extraction of aflatoxins from YES culture. The three EOs significantly inhibited the three fungal growth "Aspergillus flavus, Alternaria alternata and Fusarium oxysporum" and aflatoxin production by Aspergillus flavus. The extent inhibition of fungal growth and aflatoxin production was dependent on the type, concentration and the main active compounds of essential oil content that have an impact inhibitor against fungi.
\end{abstract}

Conclusion: The studied essential oils could inhibit all mentioned fungi moreover, rocket and thyme were more effective than parsley oil against studied fungi.

Significance and impact of the study: The use an efficient biocontrol method to reduce mycotoxigenic fungi and mycotoxins is very important to avoid the aflatoxin health hazards using safe way.

Keywords: chemical compositions, essential oils, fungi, aspergillus flavus, aflatoxins
Volume 4 Issue 4 - 2018

\author{
Ghada Al Saqqa,' Ahmed Alian, ${ }^{2}$ Ferial Ismail, ${ }^{2}$ \\ Sherif Ramzy \\ 'Food Analysis Chemistry Dept, Ministry of National Economy, \\ Gaza \\ ${ }^{2}$ Food Science and Technology Dept, Cairo University, Egypt \\ ${ }^{3}$ Food Toxicology and Contaminants Dept, National Research \\ Centre, Egypt
}

Correspondence: Sherif Ramzy, Food Toxicology and Contaminants Dept, National Research Centre, Dokki, Giza, Egypt, Tel +20100816 5828, Email sheriframzy4@gmail.com

Received: June 28, 2018 | Published: July 25, 2018

\section{Introduction}

Fungal contamination from the main causes of wheat grains induce the great economic losses and a high risk for human and animal health through the synthesis of mycotoxin., ${ }^{1,2}$

Aflatoxins are produced by many species of Aspergillus, a fungus, most notably Aspergillus flavus and Aspergillus parasiticus. ${ }^{3}$ The International Agency for Research on Cancer (IARC, 1993) ${ }^{4}$ has classified aflatoxin $\mathrm{B}_{1}$ as a group 1 carcinogen.

Essential oils have a good source of biologically active compounds. In the last years essential oils from the different plants were used in the prevention of fungal growth and mycotoxins production in cereals. ${ }^{6,7}$

In our current study, plant essential oils of rocket, parsley seeds and thyme leaves were tested as antifungal activity against fungal growth and aflatoxin production in vitro.

\section{Materials and methods}

The Parsley, rocket seeds and thyme leaves were purchased from a shop of selling herbs and medicinal plants, Cairo, Egypt, while Aspergillus flavus, Alternaria alternata and Fusarium oxysporum isolated from wheat grain samples.

\section{Extraction of essential oils}

These plant materials were milled to a fine powder in an electrical mill and extracted with hexane at room temperature and stored at $4{ }^{\circ} \mathrm{C}$ as described by Kim et al. ${ }^{8}$

\section{Chemical composition of essential oils using GC-MS}

The chemical compositions of the oils were analyzed using GCMS (Agilent; GC: 6850 Series II; MS: 5975C VL MSD) using an Agilent 19091S-433E colonna at the laboratory of Food and Feed Central Lab., Agric. Research Centre, ministry of Agric., Giza, Egypt.

The sample was injected through the auto sampler and analyzed with HP5MS column. The oven temperature was programmed as follows; $50^{\circ} \mathrm{C}$ for $4 \mathrm{~min}$, then $3^{\circ} \mathrm{C} / \mathrm{min}$ to $280^{\circ} \mathrm{C}$ for $10 \mathrm{~min}$ and $5 \mathrm{~min}$ solvent delays. Helium gas was used as a carrier gas at a flow rate of $10 \mathrm{ml} / \mathrm{min}$. The mass spectrometry detector temperature was $280^{\circ} \mathrm{C}$ and recorded at $70 \mathrm{ev}$ with scanning from 50 to $550 \mathrm{amu}$ at $3.35 \mathrm{sec}$. The identification of the compounds was based on the kovats retention index and retention time. The chemical structures of isolated the compounds were elucidated using mass spectroscopy (MS) data as reported by Adams.

\section{Preparation of potato dextrose agar (PDA)}

Thirty one g of PDA powder was transferred to a bottle and dissolved in $1 \mathrm{~L}$ distilled water by brining to boil and autoclaved for $15 \mathrm{~min}$ at $121^{\circ} \mathrm{C}$. The medium was allowed to cool and then supplemented with sterile $0.001 \%$ streptomycin. 


\section{Antifungal activity Evaluation of plant essential oils in vitro}

The antifungal activities of the tested essential oils were examined using the agar well diffusion method as described by Kacaniova et al. ${ }^{10}$ Petri dishes containing 10mL PDA were seeded with a fixed count of fungal spores. Wells of $5 \mathrm{~mm}$ diameter were done by a sterilized cork borer and the essential oils were applied at $5 \mu 1,7.5 \mu 1$ and $10 \mu 1$ from each tested essential oils.

The dishes were allowed to stand for at least $1 \mathrm{hr}$ for diffusion and then incubated for $7-10$ days at $28^{\circ} \mathrm{C}$ for Aspergillus flavus and Alternaria alternata and for $4-7$ days at $25^{\circ} \mathrm{C}$ for Fusarium oxysporum.

\section{Preparation of spore suspension}

The fungal culture was grown on PDA slants at $28^{\circ} \mathrm{C}$ for about 14 days or until good sporulation to make a fungal spore suspension.

\section{Preparation of yeast extract}

Yeast extract was prepared by adding $20 \mathrm{~g}$ yeast extract powder, $150 \mathrm{~g}$ sucrose adjusted to $1 \mathrm{~L}$ distilled water, heated to $100^{\circ} \mathrm{C}$. One hundred $\mathrm{ml}$ of liquid media were put in conical flasks and sterilized at $121^{\circ} \mathrm{C}$ for $15 \mathrm{~min}$. The flasks were cooled and $100 \mu 1$ Tween 40 was added for each. Inoculation was carried out by adding $1 \mathrm{ml}$ of a spore suspension from a toxigenic Aspergillus flavus with $50 \mu 1,75 \mu 1$ and $100 \mu 1 / 100 \mathrm{ml}$ media for each parsley, rocket and thyme oils and then incubated at $28^{\circ} \mathrm{C}$ for 15 days.

\section{Extraction and determination of aflatoxin from cultures} media

Extraction of aflatoxins from YES culture was carried out according to the method of Munimbazi and Bullerman. ${ }^{11}$ Where, the mycelium of each flask contained YES medium was harvested by filtration through filter paper, and then extracted by $100 \mathrm{ml}$ chloroform. The aflatoxins determination was done using (HPLC) according to AOAC (2007). ${ }^{12}$

\section{Statistical analysis}

All data were statistically analyzed using the General Linear Models Procedure of the Statistical Analysis System. ${ }^{13}$ All statements of significance were based on probability of $\mathrm{P}<0.05$.

\section{Results}

\section{Chemical composition of essential oils}

\section{Chemical composition of rocket seeds essential oil}

From the data presented in Table 1 the rocket essential oil contained 19 compounds, representing $99.78 \%$ of the total oil components.

Moreover, high amounts of erucic acid $45.17 \%$, followed by oleic $13.18 \%$, cis-11-eicosenoic $10.87 \%$, linoleic $4.84 \%$, 4-hydroxyphenylpyruvic $4.47 \%$, palmitic $1.43 \%$ and linolenic acid $0.99 \%$ as well asminor quantities of other essential and non-essential fatty acids.

\section{Chemical composition of thyme leaves essential oil}

Twenty-nine compounds, representing $100 \%$ of the total chemical composition, were identified in the thyme essential oil (Table 2). The main constituents of essential oil were thymol $40.98 \%$, p-cymene $15.32 \%, \gamma$-terpinene $12.01 \%$, carvacrol $2.63 \%, \alpha$-pinene $1.12 \%$ and $\alpha$-terpineol $0.33 \%$ and traces components such as, linalool 0.7 , cineole $0.41 \%$, camphor $0.3 \%$ and bornyl acetate $0.29 \%$
Table I Chemical composition of rocket seeds essential oil

\begin{tabular}{llll}
\hline No. & $\begin{array}{l}\text { RT } \\
(\mathbf{m i n})\end{array}$ & Components & $\begin{array}{l}\text { Percentage } \\
\text { composition } \\
(\%)\end{array}$ \\
\hline 1 & 3.561 & Cis-Verbenol & 0.46 \\
2 & 4.26 & Cumene,p-ethyl & 0.45 \\
3 & 10.073 & Ascorbic acid, permethyl - & 4.21 \\
4 & 11.01 & Cyanidin cation & 0.83 \\
5 & 11.625 & 4-Hydroxyphenyl pyruvic acid & 4.47 \\
6 & 15.854 & 9-Cis-Retinal & 1.24 \\
7 & 13.51 & Butylated hydroxytoluene & 0.34 \\
8 & 16.24 & 4-Hydroxy-2-methoxybenzladehyde & 1.1 \\
9 & 16.323 & Terpineol & 3.53 \\
10 & 16.817 & Palmitic acid & 1.43 \\
11 & 17.314 & Linoleic acid & 4.84 \\
12 & 18.985 & Oleic Acid & 13.18 \\
13 & 19.104 & Linolenic acid & 0.99 \\
14 & 19.621 & Rhodopin & 1.51 \\
15 & 20.876 & Colchicine & 2.2 \\
16 & 21.156 & Phytol & 1.83 \\
17 & 22.03 & Vanillic acid & 1.13 \\
18 & 22.587 & Cis-II-Eicosenoic acid & 10.87 \\
19 & 23.226 & Erucic acid & 45.17 \\
\hline & 265 & compoition & \\
\hline
\end{tabular}

Table 2 Chemical composition of thyme leaves essential oil

\begin{tabular}{llll}
\hline No. & RT (min) & Components & $\begin{array}{l}\text { Percentage } \\
\text { composition } \\
\text { (\%) }\end{array}$ \\
\hline 1 & 3.6 & P-Cymene & 15.32 \\
2 & 4.28 & Cuminaldehyde & 0.31 \\
3 & 5.821 & Gentisic acid & 0.27 \\
4 & 6.27 & $\alpha$-Terpineol,(-)- & 0.33 \\
5 & 6.404 & Trans- $\beta$-Ocimene & 1.45 \\
6 & 6.585 & Pseudolimonen & 0.76 \\
7 & 6.89 & $\alpha$-Pinene & 1.12 \\
8 & 7.662 & Cineole & 0.41 \\
9 & 8.161 & $\gamma$-terpinene & 12.01 \\
10 & 8.729 & Linalool & 0.7 \\
11 & 9.232 & Camphor & 0.3 \\
12 & 9.657 & Terpinen-4-ol & 0.68 \\
13 & 10.171 & Bornyl acetate & 0.29 \\
14 & 10.668 & Caryophyllene & 2.39 \\
15 & 12.274 & Thymol & 40.98 \\
16 & 12.785 & Carvacrol & 2.63 \\
17 & 13.799 & Ascorbic acid 6-palmitate & 1.43 \\
18 & 14.68 & Farnesol & 0.44 \\
\hline
\end{tabular}


Table Continued

\begin{tabular}{|c|c|c|c|}
\hline No. & RT (min) & Components & $\begin{array}{l}\text { Percentage } \\
\text { composition } \\
(\%)\end{array}$ \\
\hline 19 & 14.787 & 3-Octanone & 0.35 \\
\hline 20 & 16.309 & Isolongifolol & 1.98 \\
\hline 21 & 17.386 & Trans-Geranylgeraniol & 2.02 \\
\hline 22 & 18.073 & $\beta$-Citronellol & 2.18 \\
\hline 23 & 18.483 & Caryophyllene oxide & 0.45 \\
\hline 24 & 21.463 & $\begin{array}{l}\text { 3-Hydroxy-4-methoxycinnamic } \\
\text { acid }\end{array}$ & 0.13 \\
\hline 25 & 21.992 & 24,25-Dihydroxyvitamin D3 & 0.68 \\
\hline 26 & 22.48 & Retinol & 0.84 \\
\hline 27 & 22.911 & $\beta$-Carotene & 4.64 \\
\hline 28 & 23.637 & $\alpha$-Cadinol & 0.89 \\
\hline 29 & 23.991 & Rhodopin & 4.02 \\
\hline
\end{tabular}

Chemical composition of parsley seeds essential oil

The obtained data from GC: MS revealed the presence of 19 identified components, which represented $99.9 \%$ of the total amount as shown in Table 3. The main constituents of the essential oil were myristicin $34.18 \%$, $\alpha$ - pinene $16.14 \%$, apiol $15.69 \%$ and sabinene $0.68 \%$. Also, 1-allyl-2,3,4,5-tetramethoxy-benzene $9.93 \%$, $\beta$-pinene $7.3 \%, \beta$-phellandrene $4.11 \%$, carotol $2.44 \%, \beta$-myrcene $2.38 \%$, camphene $2.07 \%$ and $\alpha$-thujene $0.97 \%$ were identified.

Table 3 Chemical composition of parsley seeds essential oil

\begin{tabular}{|c|c|c|c|}
\hline No. & RT (min) & Components & $\begin{array}{l}\text { Percentage } \\
\text { composition }(\%)\end{array}$ \\
\hline 1 & 3.389 & P-Cymene & 0.26 \\
\hline 2 & 4.124 & Limonene & 0.13 \\
\hline 3 & 6.981 & $\alpha$-Pinene & 16.14 \\
\hline 4 & 7.242 & Camphene & 2.07 \\
\hline 5 & 7.739 & Sabinene & 0.68 \\
\hline 6 & 9.761 & $\beta$-pinene & 7.3 \\
\hline 7 & 10.219 & $\beta$-Myrcene & 2.38 \\
\hline 8 & 12.05 & $\beta$-Phellandrene & 4.11 \\
\hline 9 & 13.584 & $\alpha$. Thujene & 0.97 \\
\hline 10 & 14.155 & $\begin{array}{l}\text { Butylated } \\
\text { hydroxytoluene }\end{array}$ & 0.32 \\
\hline 11 & 14.39 & Carophyllene & 0.08 \\
\hline 12 & 14.708 & $\gamma$-terpinene & 0.29 \\
\hline 13 & 14.997 & P-Cymenene & 0.1 \\
\hline 14 & 15.306 & $\begin{array}{l}\text { Vitamin A acid } \\
\text { methyl ester }\end{array}$ & 0.52 \\
\hline 15 & 15.603 & Elemicin & 2.31 \\
\hline 16 & 15.877 & Myristicin & 34.18 \\
\hline 17 & 16.9 & $\begin{array}{l}\text { 1-Allyl-2,3,4,5- } \\
\text { tetramethoxy- } \\
\text { benzene }\end{array}$ & 9.93 \\
\hline 18 & 19.585 & Carotol & 2.44 \\
\hline 19 & 20.903 & Apiol & 15.69 \\
\hline
\end{tabular}

Antifungal activity of the three essential oils on the fungal growth (in vitro study)

In our current study, the essential oils of parsley, rocket seeds and thyme leaves were tested at three various concentration $5 \mu 1,7.5 \mu 1$ and $10 \mu 1 / 10 \mathrm{ml}$ for their inhibitory effect on fungal growth of Aspergillus flavus, Alternaria alternata and Fusarium oxysporum (Table 4-6).

Table 4 Antifungal activity of rocket seeds oil against Aspergillus flavus, Alternaria alternata and Fusarium

\begin{tabular}{|c|c|c|c|}
\hline \multirow{2}{*}{ Fungi spp } & \multicolumn{3}{|c|}{ Inhibition zones } \\
\hline & $5 \mu \mathrm{l} / 10 \mathrm{ml}$ & $7.5 \mu \mathrm{l} / 10 \mathrm{ml}$ & $10 \mu \mathrm{l} / 10 \mathrm{ml}$ \\
\hline Aspergillus flavus & $20.0 \pm 5.1$ & $21.0 \pm 9.3$ & $23.0 \pm 1.45$ \\
\hline Alternaria alternate & $5.8 \pm 2.60$ & $6.3 \pm 5.80$ & $7.0 \pm 1.93$ \\
\hline Fusarium oxysporum & $2.5 \pm 0.88$ & $2.8 \pm 1.89$ & $3.0 \pm 1.80$ \\
\hline
\end{tabular}

Each value represents the mean \pm standard deviation of triplicates.

Table 5 Antifungal activity of thyme leaves oil against Aspergillus flavus, Alternaria alternata and Fusarium oxysporum

\begin{tabular}{|c|c|c|c|}
\hline \multirow{2}{*}{ Fungi spp } & \multicolumn{3}{|c|}{ Inhibition zones } \\
\hline & $5 \mu \mathrm{l} / 10 \mathrm{ml}$ & $7.5 \mu \mathrm{l} / 10 \mathrm{ml}$ & $10 \mu \mathrm{l} / 10 \mathrm{ml}$ \\
\hline Aspergillus flavus & $16.5 \pm 3.6$ & $20.0 \pm 1.5$ & $22.0 \pm 3.08$ \\
\hline Alternaria alternate & $|5.0 \pm 4|$. & $15.4 \pm 1.75$ & $16.2 \pm 2.5$ \\
\hline Fusarium oxysporum & $16.0 \pm 2.08$ & $18.0 \pm 1.32$ & $19.0 \pm 0.63$ \\
\hline
\end{tabular}

Each value represents the mean \pm standard deviation of triplicates.

Table 6 Antifungal activity of parsley seeds oil against Aspergillus flavus, Alternaria alternata and Fusarium oxysporum

\begin{tabular}{|c|c|c|c|}
\hline \multirow{2}{*}{ Fungi spp } & \multicolumn{3}{|c|}{ Inhibition zones } \\
\hline & $5 \mu \mathrm{l} / 10 \mathrm{ml}$ & $7.5 \mu \mathrm{l} / \mathrm{I} 0 \mathrm{ml}$ & $10 \mu \mid / 10 \mathrm{ml}$ \\
\hline Aspergillus flavus & $8.0 \pm 1.5$ & $10.0 \pm 0.76$ & $10.0 \pm 1.55$ \\
\hline Alternaria alternate & $6.0 \pm 4.9$ & $8.0 \pm 2.7$ & $8.5 \pm 4.6$ \\
\hline Fusarium oxysporum & $13.5 \pm 1.04$ & $15.0 \pm 1.3$ & $17.0 \pm 0.63$ \\
\hline
\end{tabular}

Each value represents the mean \pm standard deviation of triplicates.

\section{Antifungal activity of rocket seeds oil on fungal growth}

The present study was conducted to assess the effect of rocket seeds oil in vitro as an antifungal agent. Antifungal activity of rocket oil was evaluated against the growth of three fungal species; Aspergillus flavus, Alternaria alternata and Fusarium oxysporum.

The data tabulated in Table 4 showed an antifungal activity of rocket oil against Aspergillus flavus, Alternaria alternata and Fusarium oxysporum. From the obtained results it could be noted that rocket essential oil at a concentration of 7.5 and $10 \mu 1 / 10 \mathrm{ml}$ showed higher antifungal activity more than the concentration of $5 \mu 1 / 10 \mathrm{ml}$.

The influence of rocket essential oil against $A$. flavus was examined and the inhibition zones were 21 and $23 \mathrm{~mm}$ for both concentrations 7.5 and $10 \mu \mathrm{l} / 10 \mathrm{ml}$, respectively. However, its inhibition zones for Alternaria alternata were 5.8, 6.3 and $7 \mathrm{~mm}$ at the three tested concentrations 5, 7.5 and $10 \mu \mathrm{l} / 10 \mathrm{ml}$, respectively. Concerning its inhibition zones for Fusarium oxysporum, they were 2.5, 2.8 and $3 \mathrm{~mm}$ 
at the three tested concentrations $5,7.5$ and $10 \mu 1 / 10 \mathrm{ml}$, respectively.

It could be concluded that the antifungal effect of rocket essential oil on the three fungal spp. were arranged as follow: A. flavus $>$ Alternaria alternata $>$ Fusarium oxysporum and the inhibitory effect of the rocket essential oil increased in proportional to its concentrations.

\section{Antifungal activity of thyme leaves oil on fungal growth}

Thyme (Thymus vulgaris) essential oil was tested at three concentrations of $5,7.5$ and $10 \mu 1 / 10 \mathrm{ml}$ to study its effect on fungal growth. The obtained results are shown in Table 5. From these results it could be noted that thyme leaves oil had an antifungal activity against the three tested fungi; Aspergillus flavus, Alternaria alternata and Fusarium oxysporum. The largest antifungal activity of thyme essential oil was observed for Aspergillus flavus at concentration of $10 \mu \mathrm{l} / 10 \mathrm{ml}$. The essential oil of thyme showed remarkable inhibition zones arranged as follow: Aspergillus flavus $>$ Fusarium oxysporum $>$ Alternaria alternata for all tested concentrations $10>7.5>5 \mu 1 / 10 \mathrm{ml}$, respectively. The fungal growth decreased with an increase of essential oil concentration.

The inhibition zones of thyme essential oil for A. flavus were 16.5, 20 and 22mm and for Alternaria alternata were 15, 15.4 and $16.2 \mathrm{~mm}$, while the inhibition zones for Fusarium oxysporum were 16, 18 and $19 \mathrm{~mm}$ at the three tested concentrations $5,7.5$ and $10 \mu 1 / 10 \mathrm{ml}$, respectively.

\section{Antifungal activity of parsley seeds oil on fungal growth}

Parsley essential oil at three concentrations $5,7.5$ and $10 \mu 1 / 10 \mathrm{ml}$ were tested as an antifungal agent and the results in Table 6 showed that parsley oil had antifungal activity against the three tested fungi; Aspergillus flavus, Alternaria alternata and Fusarium oxysporum and the best inhibition was observed against Aspergillus flavus at concentration of $10 \mu 1 / 10 \mathrm{ml}$.

Essential oil of parsley showed remarkable inhibition zone againest Fusarium oxysporum $>$ Aspergillus flavus $>$ Alternaria alternata at all tested concentrations $10>7.5>5 \mu 1 / 10 \mathrm{ml}$, respectively.

The inhibition zone caused by parsley oil against Aspergillus flavus were 8,10 and 10. However, while against Alternaria alternata were 6,8 and $8.5 \mathrm{~mm}$. Concerning, Fusarium oxysporum, they were 13.5 , 15 and 17 at three concentrations $5,7.5$ and $10 \mu 1 / 10 \mathrm{ml}$, respectively.

Effect of the tested essential oils on aflatoxin production by A. flavus

This part of our current study was conducted to reduce aflatoxin production by $A$. flavus in vitro using mentioned essential oils.

The results of aflatoxins $B_{1}, B_{2}, G_{1}$ and $G_{2}$ shows that the control sample has the highest value of total aflatoxins compared with the treated samples with tested essential oils (Table 7) and the results revealed the effect of the three essential oils at different concentrations 50,75 and $100 \mu 1 / 100 \mathrm{ml}$ on aflatoxin production by Aspergillus flavus.

Table 7 Effect of essential oils at different concentration on aflatoxin production by A. flavus

\begin{tabular}{|c|c|c|c|c|c|c|c|}
\hline Reduction\% & Total & \multicolumn{4}{|c|}{ Reduction\% } & Con. & $\begin{array}{l}\text { Essential oils } \\
\text { types }\end{array}$ \\
\hline 93.7 & 0.1 & 74.47 & 97.12 & 94 & 94.01 & 50 & \\
\hline 95.8 & 0.067 & 78.79 & 100 & 96.73 & 94.2 & 75 & Rocket \\
\hline 97.25 & 0.0439 & 82.8 & 100 & 100 & 96.37 & 100 & \\
\hline 93.77 & 0.0994 & 77.23 & 100 & 100 & 87.59 & 75 & Thyme \\
\hline 96.74 & 0.053 & 84.46 & 100 & 100 & 94.45 & 100 & \\
\hline 43.26 & 0.905 & 46.79 & 41.05 & 100 & 28.14 & 50 & \\
\hline 52.3 & 0.761 & 50.34 & 55.66 & 100 & 33.67 & 75 & Parsley \\
\hline
\end{tabular}

\section{Reduction effect of rocket seeds oil on aflatoxin production} by A. flavus

The results presented in Table 7 showed that the reduction by rocket essential oil for aflatoxins $\mathrm{B}_{1}, \mathrm{~B}_{2}, \mathrm{G}_{1}$ and $\mathrm{G}_{2}$ produced by $A$. flavus were $94.01,94,97.12$ and $74.47 \%$ at $50 \mu 1 / 100 \mathrm{ml}$, respectively, $94.2,96.73,100$ and $78.79 \%$ at $75 \mu 1 / 100 \mathrm{ml}$, respectively, and 96.37 , 100,100 and $82.8 \%$ at $100 \mu 1 / 100 \mathrm{ml}$, respectively.

The influence of rocket essential oil against total AFs production by A. flavus was evaluated and the reduction values were 93.7, 95.8 and $97.25 \%$ at the three tested concentrations, while $\mathrm{AFB}_{1}$ were reduced to reach $94.01,94.2$ and $96.37 \%$ at the three tested concentrations, respectively.
Rocket essential oil caused a $100 \%$ reduction for $\mathrm{AFB}_{2}$ at concentration of $100 \mu \mathrm{l} / 100 \mathrm{ml}$, and it caused a $100 \%$ reduction for $\mathrm{AFG}_{1}$ at both concentrations of 75 and $100 \mu \mathrm{l} / 100 \mathrm{ml}$.

The reduction effect of thyme leaves oil on aflatoxin production by $A$. flavus

The results presented in Table 7 showed the reduction effect of thyme essential oil on aflatoxins $B_{1}, B_{2}, G_{1}$ and $G_{2}$ produced by A. flavus and the reduction values were $77.36,92.74,68.142$ and $71.39 \%$ at $50 \mu 1$, while at $75 \mu 1$ they were $87.59,100,100$ and $77.23 \%$ and at $100 \mu 1$ they were $94.45,100,100$ and $84.46 \%$, for the four mentioned AFs types, respectively. Also, the results clearing that thyme essential oil at the three tested concentrations reduced the total aflatoxin production to $74.12,93.77$ and $96.74 \%$, respectively. The 
largest reduction percent was $96.74 \%$ for thyme essential oil at $100 \mu 1$ concentration.

The influence of thyme essential oil against $\mathrm{AFB}_{1}$ production by A. flavus was evaluated and the percents of inhibition were 77.36, 87.59 and $94.45 \%$ at the three tested concentrations, respectively. It is worthy to mention that thyme essential oil reduced $\mathrm{AFB}_{2}, \mathrm{AFG}_{1}$ to $100 \%$ at concentrations of 75 and $100 \mu 1 / 100 \mathrm{ml}$.

\section{Effect of parsley seeds oil on aflatoxin production by $\mathrm{A}$. flavus}

Parsley essential oil at three tested concentrations 50, 75 and $100 \mu 1 / 100 \mathrm{ml}$ was used against aflatoxins production by A. flavus. The results presented in Table 7 showed that parsley has a remarkable effect on aflatoxins production and the reduction percents were 43.26 , 52.3 and $54.17 \%$ at the three tested concentrations, respectively.

The effect of parsley essential oil on aflatoxins $B_{1}, B_{2}, G_{1}$ and $G_{2}$ production by A. flavus was studied and the reduction percent of AFs were $28.14,100,41.05$ and $46.79 \%$ at $50 \mu 1$, represented $33.67,100$, 55.66 and $50.34 \%$ at $75 \mu 1,37.35,100,55.79$ and $56.73 \%$ at $100 \mu 1$, respectively.

\section{Discussion}

The chemical analysis of rocket oil was studied by Ugur et al., ${ }^{14}$ who found that the rocket oil contain high amount of erucic acid from 46.64 to $54.79 \%$, followed by oleic $17.86-19.95 \%$, palmitic 7.25 $10.97 \%$, linoleic $4.23-9.72 \%$, and linolenic acid $1.98-3.01 \%$. While Gulfraz et al. ${ }^{15}$ found a high concentration of erucic acid $51.2 \%$ followed by oleic acid $15.1 \%$ and cis-11-eicosenoic acid $12.5 \%$.

Our obtained results are agreed with Shabnum et al., ${ }^{16-19}$ they reported that thyme oil contained thymol, $\gamma$ terpinene, $\mathrm{p}$-cymene, linalool, myrcene, $\alpha$-Pinene, $\alpha$-thujene and carvacrol at different levels.

The parsley essential oil studied by Zhang et al., ${ }^{20}$ who found five substance called myristicin $32.75 \%$, apiol $17.54 \%$, $\alpha$-pinene $16.64 \%$, $\beta$-pinene $11.54 \%$ and 1-allyl-2,3,4,5-tetramethoxy-benzene $10.0 \%$.

Many researchers believed that the antimicrobial activity of Eruca oil is mainly due to higher concentration of erucic acid, which was present in both free and triglyceride form Khoobchandani et al. ${ }^{21}$ The antifungal activities of plant extracts are most likely due to the presence of chemical compounds with antifungal properties. Particularly worth noting is erucin, which accounted for approximately $78.69 \%$ of the rocket extract and play an important role as an antifungal agent against $A$. flavus. ${ }^{22}$

Thyme essential oils are apparently amongst the best inhibitors of fungal pathogens because of the presence of the phenolic compounds such as carvacrol and thymol as main constituents which might disrupt the fungal cell membrane. Thyme oil was found to have active compounds, such as thymol and carvacrol, against a large number of microorganisms. ${ }^{6,16,17,23-25}$

The obtained results are agreed with Farah et al., ${ }^{26}$ who found that a potent effect of parsley seed extract at different concentration against Aspergillus flavus, Mucor spp. and the highest reduction was against $A$. flavus.

In our respect study Sabry $^{22}$ found that inhibition percent of $A$. flavus ability to produce aflatoxin $\mathrm{B}_{1}$ ranged from 68.42 to $100 \%$ with different concentrations of Eruca sativa ethanolic extract of 0.04 to $0.1 \%$, respectively.

El Habib ${ }^{27}$ studied the effect of the natural food additives obtained from thyme, and other medicinal plants on $\mathrm{AFB}_{1}$ produced by $A$. flavus and concluded that the inhibitory effect of the oils increased in proportion to their increased concentrations.

Sabry ${ }^{22}$ indicated the ability of parsley oil on the reduction aflatoxin $\mathrm{B}_{1}$, As well as Abdel-Khalek ${ }^{28}$ evaluated the essential oils of some Egyptian plants for novel aflatoxin $\left(\mathrm{AFB}_{1}\right)$ and ochratoxin (OTA) inhibitors, as a potent inhibitor of fungal growth.

From the obtained date could be concluded that rocket, thyme and parsley essential oils can be used against a wide range of toxiginic fungi and aflatoxin production as a safe and natural way.

\section{Acknowledgements}

Special appreciation is extended to all the laboratory teams for performing this study.

\section{Conflict of interest}

No conflict of interest is declared.

\section{References}

1. MacDonald S, Prickett TJ, Wildey KB, et al. Survey of ochratoxin A and deoxynivalenol in stored grains from the 1999 harvest in the UK. Food Addit Contam. 2004;21(2):172-181.

2. Tutelyan VA. Deoxynivalenol in cereals in Russia. Toxicol Lett. 2004;153(1):173-179.

3. Hudler G. Aspergillus species. Mold Princeton press; 1998. 48 p.

4. IARC. The International Agency for Research on Cancer. Food items and constituents, heterocyclic aromatic amines and mycotoxins, Lyon. 1993. 56:245-395.

5. Milhau G, Valentin A, Benoit F. In vitro antimicrobial activity of eight essential oils. J Essent Oil Res. 1997;9:329-333.

6. Soliman KM, Badeaa RI. Effect of oil extracted from some medicinal plants on different mycotoxigenic fungi. Food Chem Toxicol. 2002;40(11):1669-1675.

7. Irkin R, Korukluoglu M. Control of Aspergillus niger with garlic, onion and leaf extracts. Afr J Biotechnol. 2007;6:384-387.

8. Kim MK, Choi GJ, Lee HS. Fungicidal property of Curcuma longa L. rhizome-derived curcumin against phytopathogenic fungi in a greenhouse. J Agric Food Chem. 2003;51(6):1578-1581.

9. Adams RP. Identification of essential oil components by gas chromatography/ quadrupole Mass Spectroscopy. Carol Stream: Allured Publishing Corporation; 2001

10. Kacaniova M, Pavlicova S, Hascik P, et al. Microbial communities in bees, pollen and honey from Slovakia. Acta Microbiol Immunol Hung. 2009;56(3):285-295.

11. Munimbazi C, Bullerman LB. Isolation and partial characterization of antifungal metabolites of Bacillus pumilus. J Appl Microbiol. 1998;84(6):959-968.

12. AOAC. Official Methods of Analysis of AOAC International. 18th ed. Gaithersburg, MD, Method 2007.04. 2007.

13. SAS Institute, Inc. SAS User's Guide: statistics. NC: SAS Institute; 
1982.

14. Ugur A, Süntar I, Aslan S, et al. Variations in fatty acid compositions of the seed oil of Eruca sativa Mill. caused by different sowing periods and nitrogen forms. Phcog Mag. 2010;6(24):305-308.

15. Gulfraz M, Sadiq A, Tariq H. Phytochemical analysis and antibacteria activityofErucasativa aseed.PakJBot.2011;43(2):1351-1359.https://pdfs. semanticscholar.org/3588/76c0ecb66be2a69b4f5e402f917533d6854f. pdf

16. Shabnum S, Wagay MG. "Essential oil composition of Thymus vulgaris L. and their uses. J Res Dev. 2011;11:83-94.

17. Moghtader M. Antifungal effects of the essential oil from Thymus vulgaris L. and comparison with synthetic thymol on Aspergillus niger. $J$ Yeast and Fungal Res. 2012;3(6):83-88.

18. Miladi H, Slama RB, Mill D, et al. Essential oil of Thymus vulgaris L. and Rosmarinus officinalis L.: Gas chromatography-mass spectrometry analysis, cytotoxicity and antioxidant properties and antibacterial activities against foodborne pathogens. Nat Sci. 2013;5(6):729-739.

19. Juan RA, Olga PA, Mirian PP. Chemical composition and antiTrypanosoma cruzi effect of Thymus vulgaris L. (thyme) essential oil and its main component, thymol, in mice. Am J Pharm Pharmacol. 2015;2(4):21-27.

20. Zhang H, Cheng F, Wang X, et al. Evaluation of antioxidant activity of parsley (Petroselinum crispum) essential oil and identification of its antioxidants constituents. Food Res Int. 2006;39(8):833-839.

21. Khoobchandani M, Ojeswi BK, Ganesh N, et al. Antimicrobial properties and analytical profile of traditional Eruca sativa seed oil:
Comparison with various aerial and root plant extracts. Food Chem. 2010;120(1):217-224

22. Sabry BA. Evaluation of some plant extracts as antioxidants and protectors against the harmful effects of aflatoxins on albino rat. Egypt: Ph.D. Thesis, Faculty of Science, Benha University; 2011.

23. Ultee E, Smid J. Influence of carvacrol on growth and toxin production by Bacillus cereus. Int J Food Microbiol. 2001;64(3):373-378.

24. Fachini-Queiroz FC, Kummer R, Estevao-Silva CF, et al. "Effects of thymol and carvacrol, constituents of Thymus vulgaris L. essential oil, on the inflammatory response". Evidence-Based Complementary and Alternative Medicine. 2012;2012:10.

25. Nikan J, Jafari Z. In vitro anti-fungal activity of garden thyme (Thymus vulgaris L.) extract against Aspergillus flavus, the major producer of aflatoxin. J Nat Prod Plant Resour. 2015;5(2):1-5.

26. Farah H, Elbadrawy E, Ali AA. Evaluation of antioxidant and antimicrobial activities of ethanolic extracts of Parsley (Petroselinum crispum) and Coriander (Coriandrum sativum) plants grown in Saudi Arabia. Int J Adv Res. 2015;3(4):1244-1255.

27. El-Habib R. Antifungal activity of some essential oils on Aspergillus flavus growth and aflatoxin production. J Food Agric Environ. 2012;10(2):274-279.

28. Abd El-Khalek HH. Chemopreventive potential of some plant essential oils against Aspergillus flavus and Aspergillus ochraceus growth and mycotoxin production. Int J Microbiol Immunol Res. 2013;1(3):037046. 